\title{
Studies on Thermal Degradation Behavior of Siliceous Agriculture Waste (Rice Husk, Wheat Husk and Bagasse)
}

\author{
Syed H. Javed ${ }^{1}$, Umair Aslam ${ }^{1}$, Mohsin Kazmi², Masooma Rustam', Sheema Riaz², Zahid Munir ${ }^{1}$ \\ ${ }^{1}$ Department of Chemical Engineering, University of Engineering \& Technology, Lahore, Pakistan, 54890 \\ ${ }^{2}$ Department of Chemical, Polymer and Materials Engineering, University of Engineering \& Technology (Kala Shah Kaku \\ Campus), Lahore, Pakistan, 54890 \\ "Corresponding author: e-mail: umairaslam6822@gmail.com
}

\begin{abstract}
Various siliceous agriculture waste (SAW) such as rice husk, wheat husk and bagasse have been investigated to study their thermal degradation behavior using Thermogravimetric Analyzer (TGA) technique. The focus of this research is to conduct TGA of raw and acid treated $(20 \% \mathrm{HCl} \& 1 \mathrm{M} \mathrm{H} 2 \mathrm{SO} 4) \mathrm{SAW}$ at heating rate $10^{\circ} \mathrm{C} / \mathrm{min}$ in the atmosphere of nitrogen. The results were analyzed on the basis of thermograms and it was inferred that 24 hours soaking with $20 \% \mathrm{HCl}$ prior to thermal degradation enhanced the percent weight loss. The process also improved the percentage of residual weight of SAW indicating the extraction of amorphous silica with increased purity. The effect of acid treatment was verified by determining chemical composition of SAW samples before and after soaking with $20 \% \mathrm{HCl}$. Proximate analysis, thermal degradation temperature ranges and percentage of residual weight at $800^{\circ} \mathrm{C}$ for each of rice husk, wheat husk and bagasse were also quantified to observe the thermal degradation behavior. XRF analysis was performed to observe the effect of acid treatment for extraction of pure silica.
\end{abstract}

Keywords: Siliceous agriculture waste, Thermogravimetric Analyzer, amorphous silica.

\section{INTRODUCTION}

Biomass is specified as consisting of all plant and plant-derived materials including livestock manures and its structural and chemical compositions are highly variable because of environmental and genetic influences and their interactions ${ }^{1}$. Biomass is also termed as siliceous agriculture waste (SAW) as they provide silica on burning which has numerous industrial applications. In agricultural areas, biomasses are abundantly available and annual production of biomass in Pakistan is approximately 104691 thousand MT/year ${ }^{2}$. Biomass is composed of organic material, 77-80 weight percent (holocellulose, lignin etc.) and inorganic material, 18-20 weight percent (silica, alkali and alkaline earth metals etc.). When acid treated rice husk is burnt under controlled conditions, $550-800^{\circ} \mathrm{C}$, highly reactive (amorphous) and pure silica can be obtained ${ }^{3}$. If raw rice husk is burnt under uncurbed conditions then $\mathrm{K}_{2} \mathrm{O}$ dissociates due to which black particles (fixed carbon) appears in silica making it impure and converts its amorphous form to crystalline form (less reactive) ${ }^{4,5}$. If we firstly treat the rice husk with acids and then burn it, the effect of $\mathrm{K}_{2} \mathrm{O}$ and other minerals is minimized thus producing amorphous and pure silica, $4,6,7,8$.

When SAW is thermally treated, it loses weight due to drying and chemical reactions that take place by liberating volatile materials. Thermal gravimetric analysis is an analytical method which determines weight loss of SAW as a function of temperature or heating rate ${ }^{9}$. It is important to comprehend the knowledge about temperature range as high burning temperature $\left(>1000^{\circ} \mathrm{C}\right)$ will render crystalline silica and relatively low burning temperature $\left(550-800^{\circ} \mathrm{C}\right)$ will render amorphous silica ${ }^{6}$. Thermal degradation weight loss curves obtained after TGA show three phases; drying $\left(<100^{\circ} \mathrm{C}\right)$, evolution of chemically bond water, devolatilization and degradation of holocellulose $\left(100-400^{\circ} \mathrm{C}\right)$ and degradation of lignin $\left(450-650^{\circ} \mathrm{C}\right)^{10}$.

The current research work is focusing on to conduct TGA of untreated and treated rice husk along with ba- gasse and wheat straw at heating rate of $10^{\circ} \mathrm{C} / \mathrm{min}$ and to study the effect of acids treatment on the percent weight loss of volatiles, residual weight for each SAW and purity of silica. In the end, XRF analysis was also performed for rice husk.

\section{MATERIAL AND METHOD}

\section{Material}

The biomasses utilized in the research experimentation were rice husk (RH), wheat husk (WH) and bagasse (B). These biomasses were obtained from Okara District, Punjab. Chemical reagents used in the experiments were $20 \% \mathrm{HCl}, 1 \mathrm{M} \mathrm{H}_{2} \mathrm{SO}_{4}$ and distilled water.

\section{Method}

For studying the effect of hydrochloric acid and sulphuric acid on thermal degradation of SAW, fifteen samples were prepared according to the Figure 1. Actions performed on the fifteen samples of $\mathrm{RH}, \mathrm{WH}$ and $\mathrm{B}$ are summarized in Figures 2, 3 and 4 respectively against their identification. Reflex condenser apparatus is utilized for the boiling of rice husk, wheat husk and bagasse

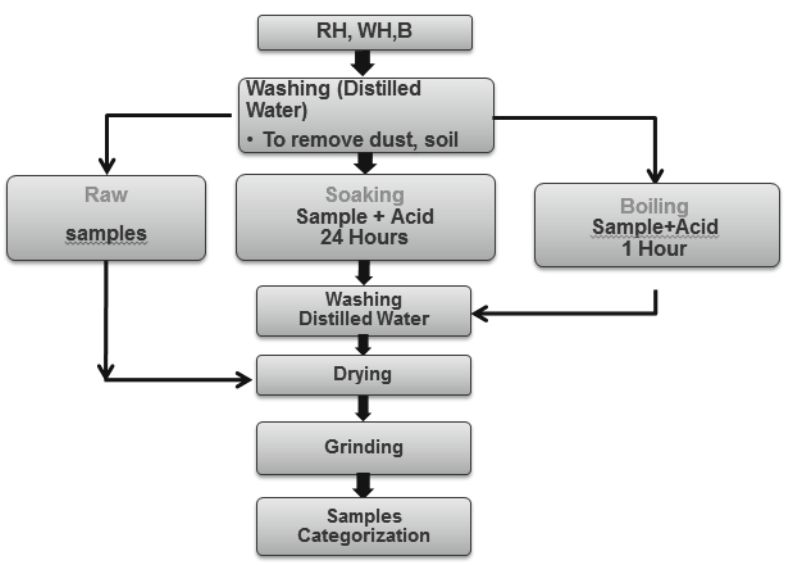

Figure 1. RH, WH and B samples preparation methodology 


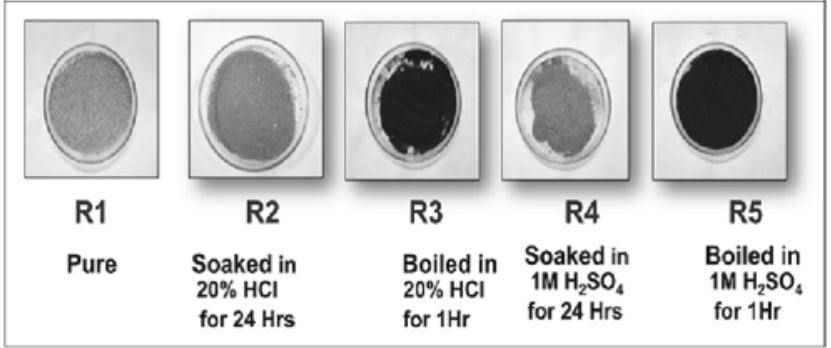

Figure 2. Rice husk samples categorization

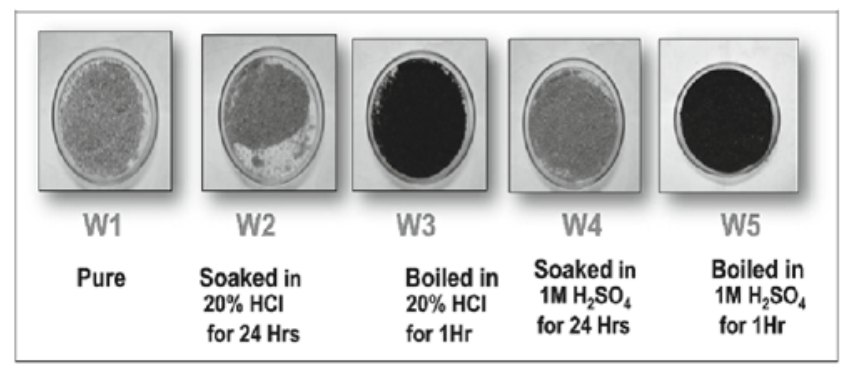

Figure 3. Wheat husk samples categorization

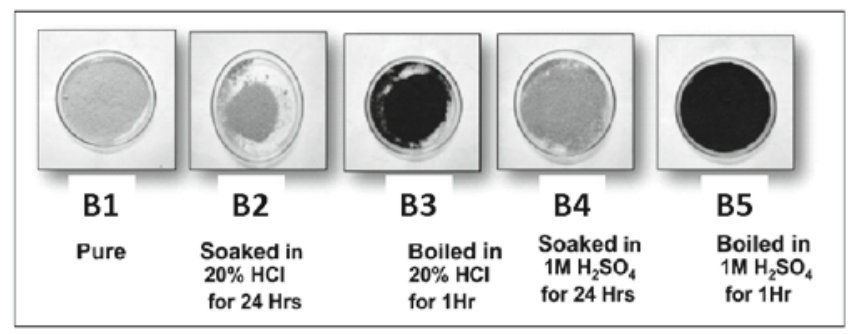

Figure 4. Bagasse samples categorization

samples. Thermal degradation behavior was studied in Thermogravimetric Analyzer (TGA) Q-50 series. XRF analysis was performed to see the effect of acid treatment on the extraction of pure silica from SAW.

Sample R1 was weighed approximately $2 \sim 10 \mathrm{mg}$ and was placed into a platinum cup which was housed in the chamber of TGA. The temperature of TGA was maintained at $10^{\circ} \mathrm{C} / \mathrm{min}$ and nitrogen flow rate at $40 \mathrm{ml} /$ min. The nitrogen flow causes the purging of volatiles that liberates during the thermal degradation process of sample under testing. When the heating temperature had risen up to $840^{\circ} \mathrm{C}$, the TGA operation was turned off. The TGA signals were sent to computer attached to TGA and all the data was recorded in tabulated form. The recorded data now was used to establish the TGA graphs (thermograms), percentage of residual weight against the temperature in ${ }^{\circ} \mathrm{C}$. This tabulated data and TGA graph were obtained and used for the data analysis and comparisons.

All the rest of the sample namely R2, R3, R4, R5, W1, W2, W3, W4, W5, B1, B2, B3, B4 and B5 were thermally degraded on the similar pattern as mentioned above for the sample R1.

\section{RESULTS AND DISCUSSION}

The results of thermogravimetric analysis have been presented in the form of TGA graphs. The TGA graphs obtained after conducting tests as per the operating conditions mentioned earlier were reproduced below.

\section{TGA Graph for RH, WH and B Samples}

It was clearly evident from Figure 5 that thermal degradation of siliceous agriculture waste rice husk occurred in three different stages. In the first stage weight loss occurred due to physically absorbed water. This phenomenon occurred in the temperature range of $40^{\circ} \mathrm{C}$ to $150^{\circ} \mathrm{C}$. Up to temperature range of $150^{\circ} \mathrm{C}$, the behavior of all the samples of rice husk whether treated or untreated was almost the same.

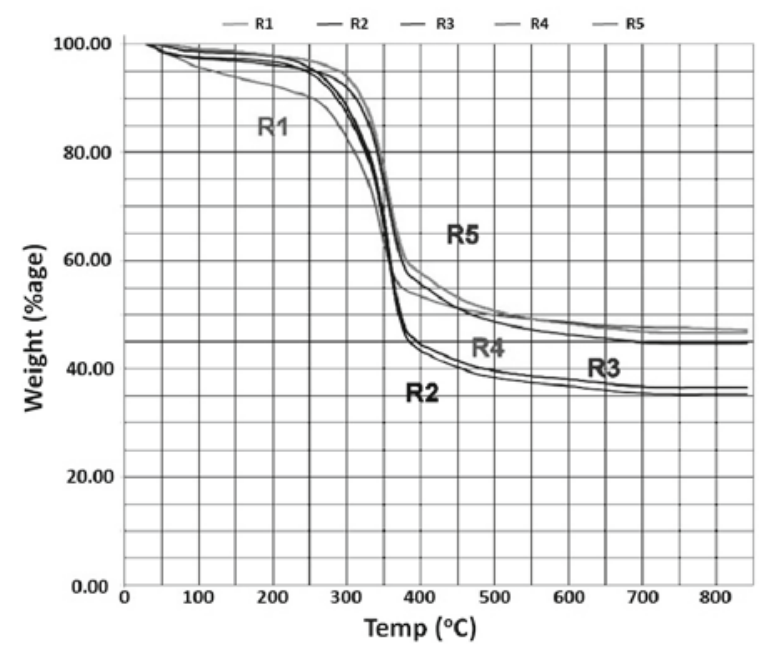

Figure 5. TGA graph for various RH samples

From the Figure 5, it was reflected that in the second stage cellulose and hemicellulose thermally degraded. Thermal degradation of cellulose and hemicellulose resulted in the formation of volatiles such as carbon dioxide, carbon monoxide and char. This phenomenon occurred in the temperature range of $150^{\circ} \mathrm{C}$ to $400^{\circ} \mathrm{C}$. Up to temperature range $400^{\circ} \mathrm{C}$, the behavior of rice husk samples started deviating from one another depending upon whether these samples were treated, untreated, soaked or boiled. It was evident from TGA graph that percent weight loss from soaked samples was maximum.

In the final and third stage of thermal degradation, lignin was observed to be thermally degraded. This phenomenon occurred in the temperature range of $400^{\circ} \mathrm{C}$ to $800^{\circ} \mathrm{C}$. It was also evident from TGA graph that thermal degradation of lignin was found to be sluggish. Thermal degradation of lignin typically took place at relatively slow rate and spread over a wide range of temperature from $400^{\circ} \mathrm{C}$ to $800^{\circ} \mathrm{C}$. Further, this stage also indicated that percent weight loss from rice husk soaked sample was on the higher side ${ }^{\mathbf{1 0}}$.

Behavior of TGA curves was similar for untreated and treated samples which showed that major contents cellulose, hemicellulose and lignin remained intact irrespective of the acid treatment. The same behavior i.e. three stages was observed with all treated and untreated samples of wheat husk and bagasse. Figure 6 and 7 show the thermograms of wheat husk and bagasse respectively.

\section{Percent Weight Losses of Volatiles for RH, WH and B} Samples

Figure 8 has indicated that the percent weight loss was maximum for the rice husk sample $\mathrm{R} 2$ at both the temperatures, $400^{\circ} \mathrm{C}$ and $800^{\circ} \mathrm{C}$. It was also concluded that after removal of volatiles, the RH is left with un- 


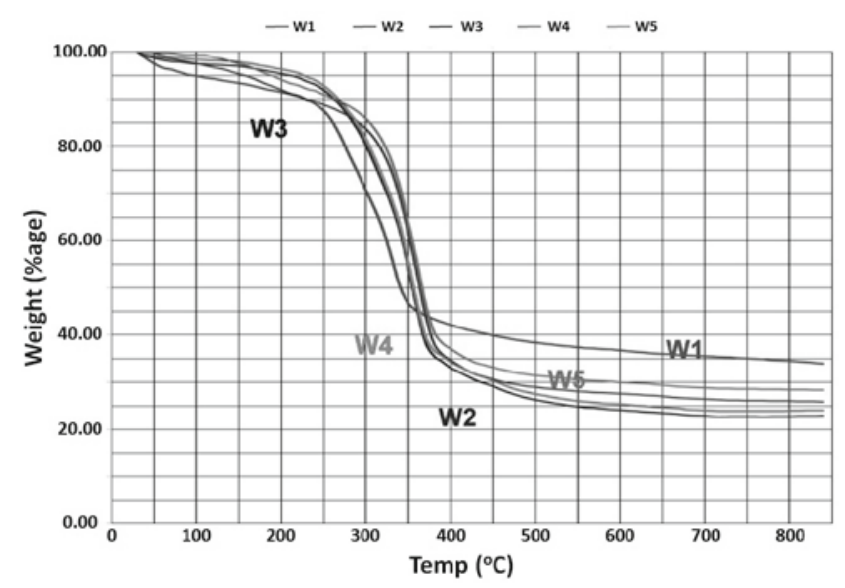

Figure 6. TGA graph for various WH samples

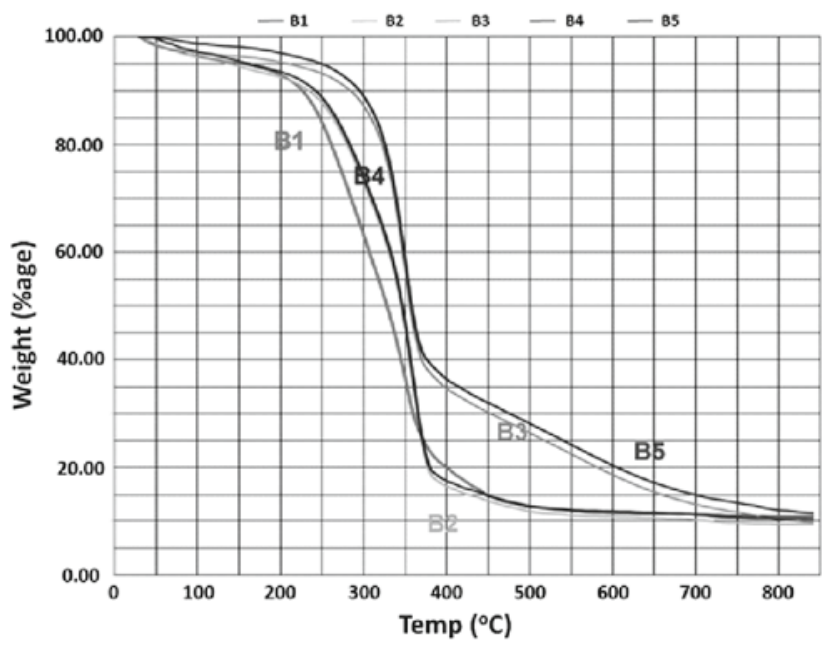

Figure 7. TGA graph for various B samples

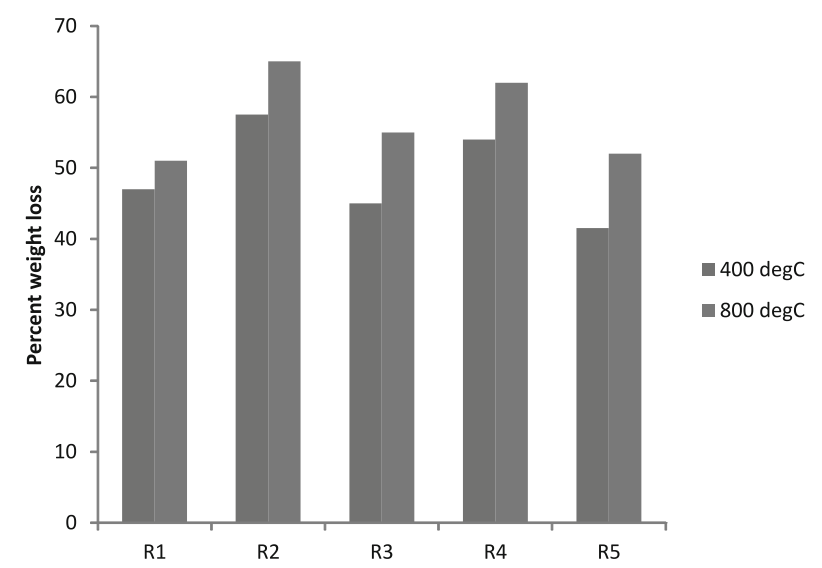

Figure 8. Percent weight loss of $\mathrm{RH}$ samples at $400^{\circ} \mathrm{C}$ and $800^{\circ} \mathrm{C}$

-burnt carbon and silica. The reason for choosing $400^{\circ} \mathrm{C}$ and $800^{\circ} \mathrm{C}$ for analysis and comparison was that maximum percent weight loss occurred at these temperature points. In case of wheat husk, maximum percent weight loss is shown by sample W2 at both temperatures i.e. 400 and $800^{\circ} \mathrm{C}$ as shown in Figure 9. While in case of bagasse, Sample B2 shows the maximum weight loss at both temperatures as reflected in Figure 10.

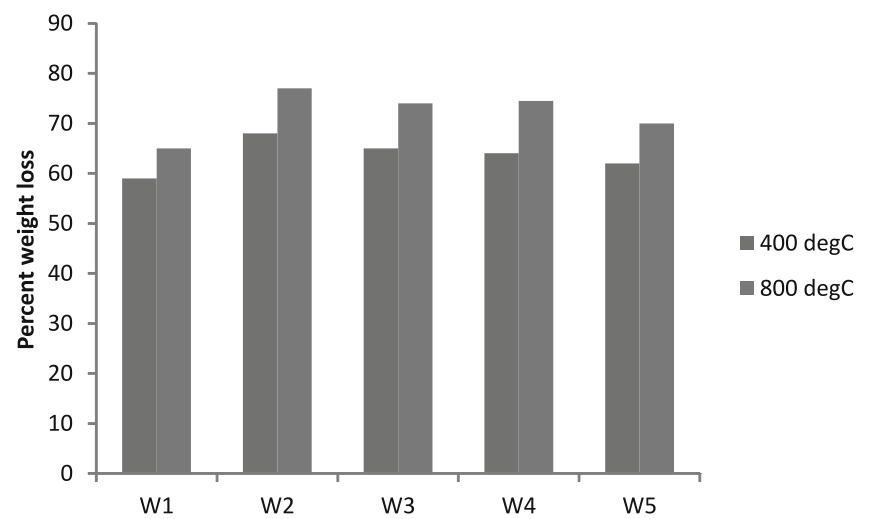

Figure 9. Percent weight loss of $\mathrm{WH}$ samples at $400^{\circ} \mathrm{C}$ and $800^{\circ} \mathrm{C}$

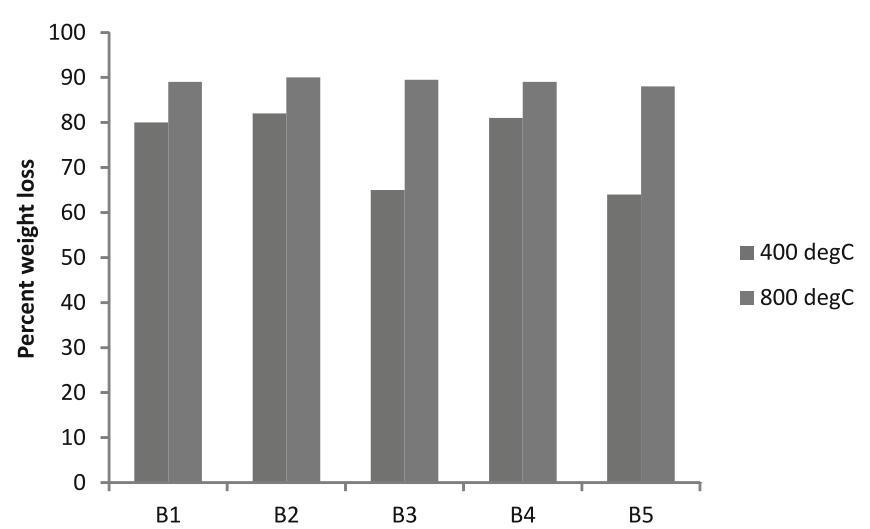

Figure 10. Percent weight loss of $\mathrm{B}$ samples at $400^{\circ} \mathrm{C}$ and $800^{\circ} \mathrm{C}$

Percentage of Residual Weight of RH, WH and B samples at $800^{\circ} \mathrm{C}$

The reason for comparing the results of residual weights for various samples of rice husk, wheat husk and bagasse at higher temperature level at $800^{\circ} \mathrm{C}$ was that industrial processes are normally designed above temperature of $700^{\circ} \mathrm{C}$ for biomass liquefaction and gasification. Figure 11 was evident that rice husk sample, R2, showed the minimum percentage of residual weight on $800^{\circ} \mathrm{C}$ as compared to other samples of rice husk. This was due the higher percent weight loss of R2 sample during the thermal degradation process. Sample, R2, was soaked in $20 \% \mathrm{HCl}$ for 24 hours. Wheat husk sample W2 and bagasse sample $\mathrm{B} 2$ showed the minimum percentage of residual weight on $800^{\circ} \mathrm{C}$ as compared to other samples of rice husk. This was due the higher percent weight loss during the thermal degradation process. These samples were soaked in $20 \% \mathrm{HCl}$ for 24 hours.

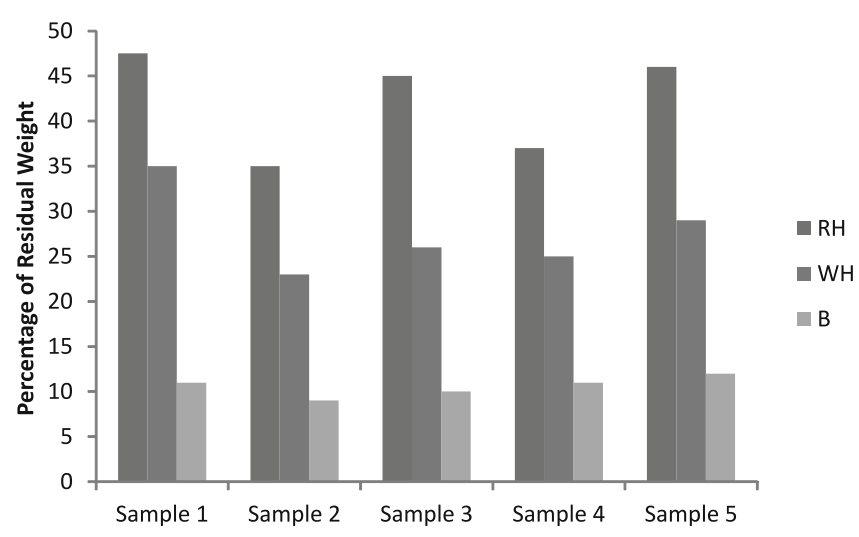

Figure 11. Percentage of residual weight of $\mathrm{RH}, \mathrm{WH}$ and $\mathrm{B}$ samples at $800^{\circ} \mathrm{C}$ 


\section{Proximate Analysis of RH, WH and B Samples from TGA}

Proximate analysis which was the determination of moisture content, volatile matter, char content and ash content was also calculated using the Figure 5, 6 and 7 , which showed the thermogravimetric analysis graphs for rice husk, wheat husk and bagasse samples. It was evident from Table 1 that volatile matter removal rate was faster in case of rice husk sample R2. This R2 sample was soaked in $20 \% \mathrm{HCl}$ for 24 hours.

It was evident from Tables 2 and 3 that volatile matter removal rate was faster in case of wheat husk W2. It was soaked in $20 \% \mathrm{HCl}$ for 24 hours. While in case of bagasse, faster volatile matter removal rate was shown by samples $\mathrm{B} 3$ and $\mathrm{B} 5$ and they were boiled in $20 \% \mathrm{HCl}$ and $1 \mathrm{M} \mathrm{H}_{2} \mathrm{SO}_{4}$ for one hour respectively.

Table 1. Proximate analysis of RH samples from TGA

\begin{tabular}{|l|c|c|c|}
\hline RH Samples & Moisture [\%] & $\begin{array}{c}\text { Volatile matter } \\
{[\%]}\end{array}$ & Char and Ash [\%] \\
\hline R1 & 6.11 & 46.47 & 47.42 \\
\hline R2 & 2.68 & 62.01 & 35.31 \\
\hline R3 & 3.09 & 52.23 & 44.68 \\
\hline R4 & 1.68 & 61.76 & 36.56 \\
\hline R5 & 1.34 & 51.98 & 46.68 \\
\hline
\end{tabular}

Table 2. Proximate analysis of WH samples from TGA

\begin{tabular}{|l|c|c|c|}
\hline WH Samples & Moisture [\%] & $\begin{array}{c}\text { Volatile matter } \\
{[\%]}\end{array}$ & $\begin{array}{c}\text { Char and Ash } \\
{[\%]}\end{array}$ \\
\hline W1 & 6.54 & 59.01 & 34.45 \\
\hline W2 & 3.03 & 74.27 & 22.70 \\
\hline W3 & 4.65 & 69.36 & 25.99 \\
\hline W4 & 2.11 & 73.99 & 23.90 \\
\hline W5 & 2.47 & 69.08 & 28.45 \\
\hline
\end{tabular}

Table 3. Proximate analysis of B samples from TGA

\begin{tabular}{|l|c|c|c|}
\hline Bagasse Samples & Moisture [\%] & Volatile matter [\%] & Char and Ash [\%] \\
\hline B1 & 4.93 & 84.25 & 10.82 \\
\hline B2 & 5.38 & 85.20 & 9.42 \\
\hline B3 & 3.77 & 85.98 & 10.25 \\
\hline B4 & 4.50 & 85.08 & 10.42 \\
\hline B5 & 1.86 & 85.92 & 12.22 \\
\hline
\end{tabular}

\section{XRF Analysis of RH sample R2 before and after soaking} with $20 \% \mathrm{HCl}$ and Thermal Degradation

Table 4 shows the XRF analysis of $\mathrm{RH}$ sample R2 was conducted before and after soaking with $20 \% \mathrm{HCl}$ for 24 hours \& performing thermal degradation using TGA. Chemical Composition of untreated RH sample contained $89.57 \% \mathrm{SiO}_{2}$ and high concentration $2.58 \%$ of impurity $\mathrm{K}_{2} \mathrm{O}$. After treatment soaking with $20 \%$ $\mathrm{HCl}, \mathrm{SiO}_{2}$ increased to $97.86 \%$ while $\mathrm{K}_{2} \mathrm{O}$ reduced to $0.47 \%$ which indicates that relatively pure silica was obtained after acid treatment. Same chemical changes are expected when wheat husk and bagasse samples are treated with acid.

\section{CONCLUSIONS}

In present research work, three different siliceous agriculture wastes were thermally degraded. General thermal degradation behavior of all treated and untreated samples of rice husk, wheat husk and bagasse was similar. At $400^{\circ} \mathrm{C}$, weight loss of three biomasses (R2, $\mathrm{W} 2$ and $\mathrm{B} 2$ ), treated with $\mathrm{HCl}$ at room temperature, is maximum. At $800^{\circ} \mathrm{C}$, again the weight loss of samples
Table 4. XRF of RH sample R2 before and after Soaking with $20 \% \mathrm{HCl}$ for $24 \mathrm{Hrs} \&$ Thermal Degradation

\begin{tabular}{|c|c|c|}
\hline $\begin{array}{l}\text { Components of } \\
\text { RH sample, R2 }\end{array}$ & $\begin{array}{l}\text { Composition of R2 } \\
\text { before soaking [\%] }\end{array}$ & $\begin{array}{c}\text { Composition of R2 } \\
\text { after soaking and TGA } \\
{[\%]}\end{array}$ \\
\hline $\mathrm{SiO}_{2}$ & 89.57 & 97.86 \\
\hline $\mathrm{K}_{2} \mathrm{O}$ & 2.58 & 0.47 \\
\hline $\mathrm{TiO}_{2}$ & 0.04 & 0.02 \\
\hline $\mathrm{Al}_{2} \mathrm{O}_{3}$ & 0.38 & 0.12 \\
\hline $\mathrm{Fe}_{2} \mathrm{O}_{3}$ & 0.43 & 0.03 \\
\hline $\mathrm{MnO}$ & 0.13 & 0.05 \\
\hline $\mathrm{MgO}$ & 0.82 & 0.09 \\
\hline $\mathrm{CaO}$ & 0.56 & 0.06 \\
\hline $\mathrm{Na}_{2} \mathrm{O}$ & 0.24 & 0.04 \\
\hline Ignition loss & 3.32 & 0.21 \\
\hline
\end{tabular}

$\mathrm{R} 2, \mathrm{~W} 2$ and $\mathrm{B} 2$ is maximum. To extract silica from SAW, it is better to soak in $\mathrm{HCl}$ instead of boiling before calcination. Thermal degradation allows the formation of silica at $650^{\circ} \mathrm{C}$ just in 1 hour. Hence energy saving is one of the important benefit of thermal degradation. Residual weights at $800^{\circ} \mathrm{C}$ in all cases are higher indicating that rate of calcination should be less than $10^{\circ} \mathrm{C} / \mathrm{min}$.

\section{ACKNOWLEDGEMENT}

Authors are thankful to the Department of Chemical Engineering, University of Engineering And Technology, Lahore Pakistan for financial and technical support.

\section{LITERATURE CITED}

1. Lee, D., Owens, V.N., Boe, A. \& Jeranyama, P. (2007). Composition of Herbaceous Biomass Feedstock, South Dakota State University, Brookings, p. 6-7.

2. Bhutto, A.W., Bazmi, A.A. \& Zahedi, G. (2011). Greener energy: Issues and challenges for Pakistan-Biomass energy prospective. Renew. Sust. Energ. Rev. 15, 3207-3219. DOI: 10.1016/j.rser.2011.04.015.

3. Bronzeoak Ltd, "Rice Husk Ash Market Study" Etsu /00/00061/Repot Dti/Pub Urn 03/668.

4. Krishnarao, R.V., Subrahmanyam, J. \& Kumar, T.J. (2001). Studies on the Formation of Black Particles in Rice Husk Silica Ash. J. Eur. Ceram. Soc. 21, 99-104. DOI: 10.1016/ S0955-2219(00)00170-9.

5. Chandrasekhar, S., Pramada, P.N. \& Praven, L. (2005). Effect of Organic Acid Treatment on the Properties of Rice Husk Silica. J. Mater. Sci. 40, 6535-6544. DOI: 10.1007/ s10853-005-1816-z.

6. Shinohara, Y. \& Kohyama, N. (2004). Quantitative Analysis of Tridymite and Cristobalite Crystallized in Rice Husk Ash by Heating. Ind. Health. 42, 277-285. DOI: 10.2486/ indhealth.42.277.

7. Yalcin, N. \& Sevinc, V. (2001). Studies on Silica Obtained from Rice Husk. Ceram. Int. 27, 219-224. DOI: 10.1016/ S0272-8842(00)00068-7.

8. Umeda, J. \& Kondoh, K. (2010). High Purification of Amorphous Silica Originated from Rice Husks by Combination of Polysaccharide Hydrolysis and Metallic Impurities Removal. Ind. Crop. Prod. 32, 539-544. DOI: 10.1016/j.indcrop.2010.07.002. 
9. Orton, "Thermogravimetric Analysis", Retrieved from www.si-mex.com.mx.

10. Aboyade, A.O., Hugo, T.J., Carrier, M., Meyer, E.L., Stahl, R., Knoetze, J.H. \& Gorgens, J.F. (2011). Non-Isothermal Kinetic Analysis of the Devolatilization of Corn Cobs And Sugar Cane Bagasse in an Inert Atmosphere. Thermochim. Acta 517, 81-89. DOI: 10.1016/j.tca.2011.01.035 